\title{
Association of the SLC45A2 gene with physiological human hair colour variation
}

\author{
Wojciech Branicki • Urszula Brudnik • \\ Jolanta Draus-Barini · Tomasz Kupiec • \\ Anna Wojas-Pelc
}

Received: 18 June 2008/ Accepted: 2 September 2008/Published online: 20 September 2008

(C) The Japan Society of Human Genetics and Springer 2008

\begin{abstract}
Pigmentation is a complex physical trait with multiple genes involved. Several genes have already been associated with natural differences in human pigmentation. The SLC45A2 gene encoding a transporter protein involved in melanin synthesis is considered to be one of the most important genes affecting human pigmentation. Here we present results of an association study conducted on a population of European origin, where the relationship between two non-synonymous polymorphisms in the SLC45A2 gene - rs26722 (E272K) and rs16891982 (L374F) - and different pigmentation traits was examined. The study revealed a significant association between both variable sites and normal variation in hair colour. Only L374F remained significantly associated with hair colour when both SNPs were included in a logistic regression model. No association with other pigmentation traits was detected in this population sample. Our results indicate that the rare allele L374 significantly increases the possibility of having black hair colour $(\mathrm{OR}=7.05)$ and thus may be considered as a future marker for black hair colour prediction.
\end{abstract}

Keywords Pigmentation - SLC45A2 - Association study · E272K $\cdot$ L374F $\cdot$ Phenotype prediction

W. Branicki $(\varangle)$ · J. Draus-Barini · T. Kupiec

Section of Forensic Genetics, Institute of Forensic Research, Westerplatte 9, 31-033 Krakow, Poland

e-mail:wbranicki@ies.krakow.pl

U. Brudnik · A. Wojas-Pelc

Department of Dermatology,

Collegium Medicum of the Jagiellonian University,

Kopernika 19, 31-501 Krakow, Poland

\section{Introduction}

Pigmentation is a complex trait that is mostly under genetic control. Differences in pigmentation were for many years a subject of research conducted in evolutionary biology and dermatology (Jablonski 2004; Rees 2004). These studies addressed many important issues, such as mechanisms of pigment formation, the role of pigment in the evolution of modern humans, its role in protection against UV light and in vitamin D synthesis, as well as cancer susceptibility associated with pigmentation status. Differences in pigmentation are mostly dependent on melanin, a highmolecular-weight polymer synthesised in melanocytes from a tyrosine precursor. The brownish-black form known as eumelanin is present in higher concentrations in individuals with darker pigmentation, whilst reddish-yellow pheomelanin is present in exceptionally high concentrations in individuals with red hair colour and fair skin (Rees 2003). Melanin is packaged into melanosomes, which, in the case of skin and hair, are passed from melanocytes to keratinocytes, which form basal and parabasal layers of the epidermis or build the shaft of the hair. It is presumed that similarly to the mouse species model, more than 120 genes are involved in determination of the significant variation that exists among humans in eye, hair, and skin coloration (Bennett and Lamoreux 2003). Until now, only a fraction of human pigment-related genes have been identified, mainly due to their DNA sequence homology with mouse pigmentation genes. Several genes have been found to strongly affect melanin synthesis (Rees 2003). Many of their variants may cause serious pigmentation disorders, but at the same time other polymorphisms may be involved in physiological pigmentation variation. MC1R has been the subject of the most thorough studies, but initial results have also been replicated in various populations for such 
genes as ASIP, OCA2, and SLC45A2 (Rees 2004; Kanetsky et al. 2002; Rebbeck et al. 2002; Frudakis et al. 2003; Bonilla et al. 2005; Duffy et al. 2007; Branicki et al. 2008; Graf et al. 2005; Fernandez et al. 2008). The MC1R gene is one of the major pigmentation genes. Genetic variation of the MC1R exon is very high among Europeans and marginal in Africans (Harding et al. 2000; Savage et al. 2008). Interestingly, R163Q MC1R polymorphism is present in about $75 \%$ of Asians, while it is relatively rare in other studied populations (in Poland allele 163Q is characteristic for approximately $4 \%$ of the population) (Branicki et al. 2007). This phenomenon may be explained by a bottleneck effect in Asia. Some allelic variants of the MC1R gene are significantly associated with the overproduction of pheomelanin and therefore red hair and fair skin colour (Rees 2003). Most studies are in agreement that MC1R is involved in malignant melanoma and basal cell carcinoma (e.g., Pastorino et al. 2004; Kanetsky et al. 2006; Brudnik et al. 2008). It is postulated that a product of the ASIP gene may antagonize MC1R receptor activation (Voisey and Van Daal 2002). Indeed, the polymorphism in the $3^{\prime}$-UTR of the ASIP gene at position 8818 has been associated with darker pigmentation in humans; thus, involvement of the ASIP gene in melanogenesis seems to be very likely (Kanetsky et al. 2002; Bonilla et al. 2005). Pathogenic mutations in the OCA2 gene are responsible for one of the most common forms of oculocutaneous albinism in humans (Oetting et al. 2005). OCA2 was also linked to natural differences in skin colour (Akey et al. 2001) and soon became considered as a major gene involved in determination of iris colour (Rebbeck et al. 2002; Frudakis et al. 2003; Duffy et al. 2007). The latest studies indicate that a significant amount of variation in eye colour is explained by an interplay between OCA2 and the gene HERC2, which is located in its neighbourhood (Kayser et al. 2008; Sturm et al. 2008). Recent genome-wide association studies (GWAS) confirmed an important role of the abovementioned and other known pigmentation genes, and also revealed additional loci and polymorphisms involved in human pigmentation (Sulem et al. 2007, 2008; Han et al. 2008). For example, additional polymorphisms within ASIP were found to be significantly associated with freckles, skin sensitivity, and hair colour, and TPCN2 was discovered as a new gene with significant contribution to pigmentation variation in humans (Sulem et al. 2008). It is noteworthy that the product of this latter gene is involved in calcium transport similarly to other known pigmentation genes SLC24A4 and SLC24A5. SLC45A2 has also been proved to have significant impact on pigmentation in humans. The product of this gene functions as a membrane transporter and is involved in melanin production. Formerly known as AIM or MATP, SLC45A2 has been widely investigated in medical and evolutionary genetics. These studies enabled association of the SLC45A2 with one of the most frequent forms of albinism in Japan (Inagaki et al. 2004). Various studies have also shown evidence for positive selection in the SLC45A2 locus (Yuasa et al 2006; Soejima et al. 2006; Sabeti et al. 2007; Lao et al. 2007). Moreover, the SLC45A2 gene has been suggested as a useful marker for ancestry inference (Yuasa et al. 2004). Interestingly, Graf et al. (2005) disclosed that some exonic polymorphisms within this locus are associated with natural differences in human pigmentation. That initial finding has recently been confirmed in other population-association studies (Han et al. 2008; Fernandez et al. 2008).

The knowledge concerning genetic determinants of pigmentation is growing rapidly and soon may find some important applications for cancer prevention as well as in forensic science for the prediction of human characteristics. Nowadays, red hair phenotype is being predicted using assays that rely on examination of the single MC1R gene, and this allows correct inference in more than $90 \%$ of cases (Grimes et al. 2001; Branicki et al. 2007). Future assays ought to be more relevant in this matter as they should take into account differences that have been noticed in red hair colour inheritance for various populations and perhaps encompass analysis of additional genes (Pastorino et al. 2004). Studies that have disclosed the significance of the HERC2 and OCA2 genes in iris colour inheritance are also a milestone towards eye colour prediction (Rebbeck et al. 2002; Frudakis et al. 2003; Kayser et al. 2008; Sturm et al. 2008).

This paper presents results of an association study carried out on a population of Europeans living in Poland. Association was examined between two missense polymorphisms within the SLC45A2 and skin type as well as hair and eye coloration.

\section{Materials and methods}

\section{Samples}

The study was approved by the Ethics Committee of the Jagiellonian University in Krakow. The examinations encompassed 392 unrelated Europeans living in the area of southern Poland who signed a written consent for use of their DNA in scientific research. Following sample collection (buccal swabs), a detailed phenotype examination was performed by a single dermatologist. The data included gender, age, eye colour (blue/grey, green, hazel, brown/black), hair colour (red, blond, dark blond/brown, auburn, black) and skin colour (fair including subjects with I or II phototype and dark including subjects with III or IV phototype according to the Fitzpatrick scale) (Fitzpatrick 1988). 
Genotyping

DNA was extracted with the organic or silica-based method and quantified using the fluorimetric method as described elsewhere (Branicki et al. 2008). Samples were then subjected to multiplex PCR amplification using a Qiagen Multiplex PCR kit (Qiagen, Hilden, Germany). The total reaction volume was $10 \mu \mathrm{l}$, and the reaction mixture consisted of $5 \mu$ of Qiagen Master Mix, about 1-10 ng of template DNA, primer premix (final concentration $0.125 \mu \mathrm{M}$ for each primer), and DNase free water. Primers for rs 26722 were according to Yuasa et al. (2004) (for: AGAGGTTGCAAAGGGCATTC and rev: CCCATGAA ACTCTTCTCGTCAA) and for rs16891982 according to Inagaki et al. (2004) (for: AGAGGTGGAGAAGCAGA GTG and rev: GAAGACATCCTTAGGAGAGAG). Thirty-two amplification cycles were applied using a temperature profile as recommended by the PCR kit producer and annealing temperature set at $58^{\circ} \mathrm{C}$. A total of $5 \mu \mathrm{l}$ of PCR products was used for evaluation of the PCR efficiency, and the remaining $5 \mu \mathrm{l}$ was purified using an ExoSap IT kit (Amersham Pharmacia, Freiburg, Germany). The purified PCR products were then subjected to minisequencing using a developed multiplex $\mathrm{SNaPshot}$ protocol. Extension reactions were composed of $2 \mu \mathrm{l}$ of SNaPshot mix, $1 \mu \mathrm{l}$ of extension primer premix, $1 \mu \mathrm{l}$ of purified PCR product, and DNase free water up to $10 \mu \mathrm{l}$ (Applied Biosystems, Foster City, CA). The extension primer sequences and final concentrations were as follows: rs26722: GTCTGACAAGTACGAGTATGGTTCTATC $(0.5 \mu \mathrm{M})$, rs 16891982: AAGTCTGACAAGGAAAACAC GGAGTTGATGCA $(0.25 \mu \mathrm{M})$, where the underlined fragment is a target sequence and the remaining part is a universal tail. Products of minisequencing reactions were purified with SAP enzyme (Fermentas, Vilnius, Lithuania) and analysed on an ABI 3100 Avant genetic analyser with the appropriate protocol for SNP analysis. All amplification and minisequencing reactions were carried out on a GenAmp 9700 thermocycler (Applied Biosystems, Foster City, CA).

\section{Statistical analyses}

The obtained genotyping data were tested for agreement with Hardy-Weinberg expectations using the exact test, and the degree of linkage disequilibrium between the two analysed SNPs was evaluated with the permutation test using the EM algorithm as implemented in Arlequin software 3.1 (Excoffier et al. 2005). The analysed positions were subjected to analysis for their association with different pigment traits using the $\chi^{2}$ test, and then the odds ratio effect of SLC45A2 gene variants on hair colour was evaluated, and a logistic regression model including both the SNPs was built, in all cases with the help of the SPSS 12.0 computer program.

\section{Results and discussion}

The studied population consisted of 238 females and 154 males of European origin. Fair skin (phototype I or II) was characteristic for $44.1 \%$ of individuals, while $55.9 \%$ of individuals had darker skin colour (phototypes III and IV). Most of the individuals (55.6\%) were classified in a group of blue/grey iris colour, $11.7 \%$ had green, $20.9 \%$ hazel, and $11.7 \%$ brown eye colour. The most frequent hair colour was dark blond/brown (46.9\%) and then blond (15.8\%), black (12.8\%), auburn (3.1\%). The population sample was overrepresented by red-haired individuals $(21.4 \%)$.

We studied two non-synonymous positions (rs26722 and rs16891982) within gene SLC45A2. The SLC45A2 is located on chromosome $5(5 \mathrm{p} 13.3)$ and contains seven exons spanning a region of approximately $40 \mathrm{~kb}$ and encodes a 530 amino-acid protein that is supposed to have 12 transmembrane domains. It has been shown that the mouse homolog is involved in processing and intracellular trafficking of tyrosinase, one of the crucial enzymes required for melanin synthesis (Costin et al. 2003). The examined polymorphisms were located in exons 3 and 5 and refer to amino-acid changes E272K and L374F, respectively. Both studied SNPs were found to be in HW equilibrium (Table 1). The population frequencies for both SNPs were similar to those characteristic for other populations of European descent (Table 1). In a large population study, Yuasa et al. (2006) showed that in the case of L374F substitution, Germans had a significantly higher frequency of the 374F allele than French and Italians. Our study indicates that the Polish population sample is very similar to the German sample in this respect, as the frequency of the $374 \mathrm{~F}$ allele was estimated at 0.977 for Poles compared to 0.965 for Germans (Yuasa et al. 2006). Various studies confirmed significant differences in frequencies of this

Table 1 The investigated SNPs, allele frequencies, and results of HW test

\begin{tabular}{llllll}
\hline GenBank ID & Amino-acid change & Gene location & Nucleotide substitution and frequency & HW $(P$ value $)$ \\
\hline rs26722 & E272K & Exon 3 & $\mathrm{G}=0.985$ & $\mathrm{~A}=0.015$ & 1.0 \\
rs16891982 & L374F & Exon 5 & $\mathrm{G}=0.023$ & $\mathrm{C}=0.977$ & 0.18 \\
\hline
\end{tabular}


allele among various ethnic groups (Graf et al. 2005; Yuasa et al. 2006; Soejima et al. 2006). Yuasa et al. (2004) analysed polymorphisms in Germans and Japanese and proposed the rs 16891982 to be a useful marker for ancestry inference. The population frequency of the minor $272 \mathrm{~K}$ allele was found to be slightly lower in the Polish population sample compared to the German population $(0.015$ and 0.033, respectively) (Yuasa et al. 2006).

An increased proportion of allelic variants L374 and $272 \mathrm{~K}$ was found in individuals with black hair compared with those with other hair colours (Table 2). The association was stronger for the L374F variable site $\left(\chi^{2}=18.792\right.$, $P<0.0001)$ than for the E272K $\left(\chi^{2}=9.298, P=0.002\right)$. Our results indicate that the rare allele L374 significantly increases the possibility of having black hair colour $(\mathrm{OR}=7.05,95 \% \mathrm{CI}, 2.580-19.253)$. Odds ratio for the $272 \mathrm{~K}$ was estimated at 5.32, 95\% CI, 1.619-17.463. The two analysed SNPs were found to be in extensive linkage disequilibrium $\left(\chi^{2}=70.939, \quad P<0.000001\right)$, which brought into question their independent influence on hair

Table 2 SLC45A2 variants and phenotypic features

\begin{tabular}{|c|c|c|c|c|}
\hline \multirow[t]{3}{*}{ Trait } & \multicolumn{4}{|c|}{ SLC45A2 variant } \\
\hline & \multicolumn{2}{|l|}{$\mathrm{E} 272 \mathrm{~K}$} & \multicolumn{2}{|l|}{ L374F } \\
\hline & $\mathrm{E} / \mathrm{E}$ & $\mathrm{E} / \mathrm{K}$ or $\mathrm{K} / \mathrm{K}$ & $\mathrm{F} / \mathrm{F}$ & $\mathrm{L} / \mathrm{F}$ or $\mathrm{L} / \mathrm{L}$ \\
\hline \multicolumn{5}{|l|}{ Gender } \\
\hline Male & $147(95.5 \%)$ & $7(4.5 \%)$ & $146(94.8 \%)$ & $8(5.2 \%)$ \\
\hline Female & $233(97.9 \%)$ & $5(2.1 \%)$ & $229(96.2 \%)$ & $9(3.8 \%)$ \\
\hline \multicolumn{5}{|l|}{ Age (years) } \\
\hline$<30$ & $60(96.8 \%)$ & $2(3.2 \%)$ & $60(96.8 \%)$ & $2(3.2 \%)$ \\
\hline $30-39$ & $31(100 \%)$ & $0(0 \%)$ & $29(93.5 \%)$ & $2(6.5 \%)$ \\
\hline $40-49$ & $42(100 \%)$ & $0(0 \%)$ & $42(100 \%)$ & $0(0 \%)$ \\
\hline $50-59$ & $57(95 \%)$ & $3(5 \%)$ & $55(91.7 \%)$ & $5(8.3 \%)$ \\
\hline $60-69$ & $72(98.6 \%)$ & $1(1.4 \%)$ & $71(97.3 \%)$ & $2(2.7 \%)$ \\
\hline$>70$ & $118(95.2 \%)$ & $6(4.8 \%)$ & $118(95.2 \%)$ & $6(4.8 \%)$ \\
\hline \multicolumn{5}{|l|}{ Hair colour } \\
\hline Red & $81(96.4 \%)$ & $3(3.6 \%)$ & $81(96.4 \%)$ & $3(3.6 \%)$ \\
\hline Blond & $62(100 \%)$ & $0(0 \%)$ & $61(98.4 \%)$ & $1(1.6 \%)$ \\
\hline Dark blond/brown & $180(97.8 \%)$ & $4(2.2 \%)$ & $179(97.3 \%)$ & $5(2.7 \%)$ \\
\hline Auburn & $12(100 \%)$ & $0(0 \%)$ & $12(100 \%)$ & $0(0 \%)$ \\
\hline Black & $45(90 \%)$ & $5(10 \%)$ & $42(84 \%)$ & $8(16 \%)$ \\
\hline \multicolumn{5}{|l|}{ Eye colour } \\
\hline Blue or grey & $214(98.2 \%)$ & $4(1.8 \%)$ & $211(96.8 \%)$ & $7(3.2 \%)$ \\
\hline Green & $42(91.3 \%)$ & $4(8.7 \%)$ & $43(93.5 \%)$ & $3(6.5 \%)$ \\
\hline Hazel & $79(96.3 \%)$ & $3(3.7 \%)$ & $77(93.9 \%)$ & $5(6.1)$ \\
\hline Brown or black & $45(97.8 \%)$ & $1(2.2 \%)$ & $44(95.7 \%)$ & $2(4.3 \%)$ \\
\hline \multicolumn{5}{|l|}{ Skin colour } \\
\hline Fair skin (I/II) & $169(97.7 \%)$ & $4(2.3 \%)$ & $166(96 \%)$ & $7(4.0 \%)$ \\
\hline Dark skin (III/IV) & $211(96.3 \%)$ & $8(3.7 \%)$ & $209(95.4 \%)$ & $10(4.6 \%)$ \\
\hline
\end{tabular}

colour. Others also reported that these two SNPs were in complete LD (Graf et al. 2005; Soejima et al. 2006). Notably, only position L374F remained significantly associated with hair colour when two SNPs were included in a logistic regression model $(P=0.0087$; OR $=8.4)$. Moreover, Soejima et al. (2006) discussed that while the L374 allele is ancestral, the $272 \mathrm{~K}$ allele is derived and has rather low frequency among Africans. Graf et al. (2005) noticed that the frequency of the $272 \mathrm{~K}$ allele characteristic for the Australian Aborigine population was very similar to the frequency estimated for the Caucasian population, although these ethnic groups differ significantly in pigmentation phenotype. All these findings strongly support the hypothesis that the action of the L374F is crucial for variation in pigmentation in European populations, while the $272 \mathrm{~K}$ has been linked with pigment differences due to tight LD observed between these two SNPs.

In the present study, $\chi^{2}$ testing for association between L374F, E272K, and skin colour and eye colour did not support any relationship. This is contrary to Graf et al. (2005) as they found that these two SNPs were significantly associated with skin, eye, and hair colour in Caucasians, and the strongest relationship was noted for both skin and hair colour. These results were recently replicated by others. Han et al. (2008) found that rs16891982 (L374F) is associated with hair and skin colour as well as tanning ability. Fernandez et al. (2008) also observed that the L374 allele is linked with darker pigmentation and moreover plays a protective role from malignant melanoma. This unexpected partial discordance between our and other results may be caused by difficulties with replication of association studies. Such problems are commonly observed (Gorroochurn et al. 2007) and may be explained by different factors, e.g., interpopulation differences in allele frequency or LD structure, hidden population stratification, or allelic heterogeneity (Neale and Sham 2004), as well as interactions between genes (Moore 2003). Indeed, although the numbers of analysed samples are similar in this study and in Graf et al., the frequency of the minor allele L374 is lower in case of our population sample (0.023 vs. 0.066 in Graf et al. 2005). Hence, the most possible reason for the observed discrepancy is a lack of power to detect the association with skin colour due to very low frequency of the L374 allele in our population. Hair is understood as a form of epidermis, and both hair and skin pigmentations are similar processes involving pigment transfer from melanocytes to keratinocytes (Rees 2003). Hence, it is not surprising that in most cases black-haired individuals have darker skin colour. However, association between dark hair and dark skin colour is not a rule, and in case of the studied population $16 \%$ of individuals had black hair and fair skin (phototype II). This means that these two features must be at least to some degree under control of different genes. 
Indeed, some studies have shown that different pigmentation genes may, to a varying degree, affect separate pigmentation features. The MC1R gene, for example, has a predominant role in red hair colour inheritance and is considered to be a major gene involved in skin colour variation. Numerous studies have negated involvement of this gene in determination of iris colour variation (Branicki et al. 2005). Initial data suggest that epistatic interactions between different genes may also play an important role in eventual determination of phenotypic features (Akey et al. 2001; Pastorino et al. 2004). Pastorino et al. (2004) suggested that MC1R variants that are responsible for red hair colour determination may be masked by other genes in populations with darker pigmentation. However, in the present study, $3.6 \%$ of red-haired individuals were found to have the L374 allele associated with darker pigmentation. All of them had two MC1R alterations, which are considered as major function mutations strongly affecting receptor performance (data not present). All these individuals had fair skin and blue eyes. This indicates a predominant role of the MC1R gene.

Numerous mutations in the SLC45A2 have been associated with strong melanin deficiency in humans, defined as oculacutaneous albinism type 4; thus, its important role in melanin synthesis is undisputable (Inagaki et al. 2004; Rundshagen et al. 2004; Inagaki et al. 2006). So far, only one exonic SLC45A2 variant has been confirmed to be involved in normal pigment variation. Increasing attention in genotype/phenotype association studies is, however, being paid to gene regulatory regions. For example, HERC2 is supposed to influence eye colour by inhibition of the OCA2 gene expression (Eiberg et al. 2008; Sturm et al. 2008). Han et al. (2008) suggested involvement of IRF4 in hair colour, skin colour, and eye colour determination. Interestingly, IRF4 encodes a transcription factor affecting gene expression in response to interferon and other cytokines. One study showed that polymorphisms in the promoter region of the SLC45A2 gene are involved in normal variation of human pigmentation. These polymorphisms were found not to be in LD with L374F, thus were suggested to independently affect phenotypic features (Graf et al. 2007). In that study the SLC45A2 promoter positions were associated only with skin colour differences and not with eye or hair colour. It is noteworthy that Han et al. (2008) recently analysed both the exonic and promoter SLC45A2 SNPs discovered by Graf's team and using multivariable analysis showed that only L374F remained significantly associated with pigmentation.

The present study provided further evidence supporting the previous findings of the significance of the rs 16891982 (L374F) within the SLC45A2 gene in physiological variation of human pigmentation. In the studied population sample of European ancestry, rs16891982 was found to be significantly associated with hair colour. Further functional studies are necessary to confirm that the L374F is indeed a causal variant within the SLC45A2 gene.

Acknowledgments We would like to thank all volunteers who participated in this investigation and donated biological samples. We also wish to thank Ronan Doyle, Olga Rydzyk, and Magda Łacka for their contribution to this project. The study was supported by the Ministry of Science and Higher Education, grant no. 0T00C01829 and by the Institute of Forensic Research in Krakow, grant no. I/G/2007.

\section{References}

Akey JM, Wang H, Xiong M, Wu H, Liu W, Shriver MD, Jin L (2001) Interaction between the melanocortin-1 receptor and $\mathrm{P}$ genes contributes to inter-individual variation in skin pigmentation phenotypes in a Tibetan population. Hum Genet 108:516-520

Bennett DC, Lamoreux ML (2003) The color loci of mice-a genetic century. Pigment Cell Res 16:333-344

Bonilla C, Boxill LA, Donald SA, Williams T, Sylvester N, Parra EJ, Dios S, Norton HL, Shriver MD, Kittles RA (2005) The 8818G allele of the agouti signaling protein (ASIP) gene is ancestral and is associated with darker skin color in African Americans. Hum Genet 116:402-406

Branicki W, Brudnik U, Wojas-Pelc A (2005) Genetic prediction of pigmentary traits in forensic studies. Probl Forensic Sci 64:343357

Branicki W, Brudnik U, Kupiec T, Wolanska-Nowak P, Wojas-Pelc A (2007) Determination of phenotype associated SNPs in the MC1R gene. J Forensic Sci 52:349-354

Branicki W, Brudnik U, Kupiec T, Wolańska-Nowak P, Szczerbińska A, Wojas-Pelc A (2008) Association of polymorphic sites in the OCA2 gene with eye colour using the tree scanning method. Ann Human Genet 72:184-192

Brudnik U, Branicki W, Wojas-Pelc A, Kanas P (2008) The contribution of melanocortin 1 receptor gene polymorphisms and the agouti signalling protein gene $8818 \mathrm{~A}>\mathrm{G}$ polymorphism to cutaneous melanoma and basal cell carcinoma in a Polish population. Exp Dermatol. doi: 10.1111/j.1600-0625.2008.00760.x

Costin GE, Valencia JC, Vieira WD, Lamoreux ML, Hearing VJ (2003) Tyrosinase processing and intracellular trafficking is disrupted in mouse primary melanocytes carrying the underwhite (uw) mutation A model for oculocutaneous albinism (OCA) type 4. J Cell Sci 116:3203-3212

Duffy DL, Montgomery GW, Chen W, Zhao ZZ, Le L, James MR, Hayward NK, Martin NG, Sturm RA (2007) A three-singlenucleotide polymorphism haplotype in intron 1 of OCA2 explains most human eye-color variation. Am J Hum Genet 80:241-252

Eiberg H, Troelsen J, Nielsen M, Mikkelsen A, Mengel-From J, Kjaer KW, Hansen L (2008) Blue eye color in humans may be caused by a perfectly associated founder mutation in a regulatory element located within the HERC2 gene inhibiting OCA2 expression. Hum Genet 123(2):177-187

Excoffier L, Laval G, Schneider S (2005) Arlequin ver 30: an integrated software package for population genetics data analysis. Evol Bioinform Online 1:47-50

Fernandez LP, Milne RL, Pita G, Avilés JA, Lázaro P, Benítez J, Ribas G (2008) SLC45A2: a novel malignant melanomaassociated gene. Hum Mutat 29(9):1161-1167. doi:10.1002/ humu.20804

Fitzpatrick TB (1988) The validity and practicability of sun-reactive skin types I through VI. Arch Dermatol 124:869-871 
Frudakis T, Thomas M, Gaskin Z, Venkateswarlu K, Chandra KS, Ginjupalli S, Gunturi S, Natrajan S, Ponnuswamy VK, Ponnuswamy KN (2003) Sequences associated with human iris pigmentation. Genetics 165:2071-2083

Gorroochurn P, Hodge SE, Heiman GA, Durner M, Greenberg DA (2007) Non-replication of association studies: "pseudo-failures" to replicate? Genet Med 9:325-331

Grimes EA, Noake PJ, Dixon L, Urquhart A (2001) Sequence polymorphism in the human melanocortin 1 receptor gene as an indicator of the red hair phenotype. Forensic Sci Int 122:124-129

Graf J, Hodgson R, van Daal A (2005) A single nucleotide polymorphisms in the MATP gene are associated with normal human pigmentation variation. Hum Mutat 25:278-284

Graf J, Voisey J, Hughes I, van Daal A (2007) Promoter polymorphisms in the MATP (SLC45A2) gene are associated with normal human skin color variation. Hum Mutat 28:710-717

Han J, Kraft P, Nan H, Guo Q, Chen C, Qureshi A, Hankinson SE, Hu FB, Duffy DL, Zhao ZZ, Martin NG, Montgomery GW, Hayward NK, Thomas G, Hoover RN, Chanock S, Hunter DJ (2008) A genome-wide association study identifies novel alleles associated with hair color and skin pigmentation. PLoS Genet 16(5): 1000074

Harding RM, Healy E, Ray AJ, Ellis NS, Flanagan N, Todd C, Dixon C, Sajantila A, Jackson IJ, Birch-Machin MA, Rees JL (2000) Evidence for variable selective pressures at MC1R. Am J Hum Genet 66:1351-1361

Inagaki K, Suzuki T, Shimizu $\mathrm{H}$, Ishii $\mathrm{N}$, Umezawa $\mathrm{Y}$, Tada J, Kikuchi N, Takata M, Takamori K, Kishibe M, Tanaka M, Miyamura Y, Ito S, Tomita Y (2004) Oculocutaneous albinism type 4 is one of the most common types of albinism in Japan. Am J Hum Genet 74:466-471

Inagaki K, Suzuki T, Ito S, Suzuki N, Adachi K, Okuyama T, Nakata Y, Shimizu H, Matsuura H, Oono T, Iwamatsu H, Kono M, Tomita Y (2006) Oculocutaneous albinism type 4: six novel mutations in the membrane-associated transporter protein gene and their phenotypes. Pigment Cell Res 19:451-453

Jablonski N (2004) The evolution of human skin and skin color. Annu Rev Anthropol 2004:585-624

Kanetsky PA, Swoyer J, Panossian S, Holmes R, Guerry D, Rebbeck TR (2002) A polymorphism in the agouti signaling protein gene is associated with human pigmentation. Am J Hum Genet 70:770-775

Kanetsky PA, Rebbeck TR, Hummer AJ, Panossian S, Armstrong BK, Kricker A, Marrett LD, Millikan RC, Gruber SB, Culver HA, Zanetti R, Gallagher RP, Dwyer T, Busam K, From L, Mujumdar U, Wilcox H, Begg CB, Berwick M (2006) Population-based study of natural variation in the melanocortin-1 receptor gene and melanoma. Cancer Res 66:9330-9337

Kayser M, Liu F, Janssens AC, Rivadeneira F, Lao O, van Duijn K, Vermeulen M, Arp P, Jhamai MM, van Ijcken WF, den Dunnen JT, Heath S, Zelenika D, Despriet DD, Klaver CC, Vingerling JR, de Jong PT, Hofman A, Aulchenko YS, Uitterlinden AG, Oostra BA, van Duijn CM (2008) Three genome-wide association studies and a linkage analysis identify HERC2 as a human iris color gene. Am J Hum Genet 82:411-423

Lao O, de Gruijter JM, van Duijn K, Navarro A, Kayser M (2007) Signatures of positive selection in genes associated with human skin pigmentation as revealed from analyses of single nucleotide polymorphisms. Ann Hum Genet 71:354-369

Moore JH (2003) The ubiquitous nature of epistasis in determining susceptibility to common human diseases. Hum Hered 56:73-82

Neale BM, Sham PC (2004) The future of association studies: genebased analysis and replication. Am J Hum Genet 75:353-362
Oetting WS, Garrett SS, Brott M, King RA (2005) P gene mutations associated with oculocutaneous albinism type II (OCA2). Hum Mutat 25:323-329

Pastorino L, Cusano R, Bruno W, Lantieri F, Origone P, Barile M, Gliori S, Shepherd GA, Sturm RA, Bianchi-Scarra G (2004) Novel MC1R variants in Ligurian melanoma patients and controls. Hum Mutat 24:103-112

Rebbeck TR, Kanetsky PA, Walker AH, Holmes R, Halpern AC, Schuchter LM, Elder DE, Guerry D (2002) P gene as an inherited biomarker of human eye color. Cancer Epidemiol Biomarkers Prev 11:782-784

Rees JL (2003) Genetics of hair and skin color. Annu Rev Genet 37:67-90

Rees JL (2004) The genetics of sun sensitivity in humans. Am J Hum Genet 75:739-751

Rundshagen U, Zühlke C, Opitz S, Schwinger E, Käsmann-Kellner B (2004) Mutations in the MATP gene in five German patients affected by oculocutaneous albinism type 4. Hum Mutat 23:106110

Sabeti PC, Varilly P, Fry B, Lohmueller J, Hostetter E, Cotsapas C, Xie X, Byrne EH et al (2007) Genome-wide detection and characterization of positive selection in human populations. Nature 449:913-918

Savage SA, Gerstenblith MR, Goldstein AM, Mirabello L, Fargnoli MC, Peris K, Landi MT (2008) Nucleotide diversity and population differentiation of the melanocortin 1 receptor gene, MC1R. BMC Genet 10:31

Soejima M, Tachida H, Ishida T, Sano A, Koda Y (2006) Evidence for recent positive selection at the human AIM1 locus in a European population. Mol Biol Evol 23:179-188

Sturm RA, Duffy DL, Zhao ZZ, Leite FP, Stark MS, Hayward NK, Martin NG, Montgomery GW (2008) A single SNP in an evolutionary conserved region within intron 86 of the HERC2 gene determines human blue-brown eye color. Am J Hum Genet $82: 424-431$

Sulem P, Gudbjartsson DF, Stacey SN, Helgason A, Rafnar T, Magnusson KP, Manolescu A, Karason A, Palsson A, Thorleifsson G, Jakobsdottir M, Steinberg S, Pálsson S, Jonasson F, Sigurgeirsson B, Thorisdottir K, Ragnarsson R, Benediktsdottir KR, Aben KK, Kiemeney LA, Olafsson JH, Gulcher J, Kong A, Thorsteinsdottir U, Stefansson K (2007) Genetic determinants of hair, eye and skin pigmentation in Europeans. Nat Genet 39:1443-1452

Sulem P, Gudbjartsson DF, Stacey SN, Helgason A, Rafnar T, Jakobsdottir M, Steinberg S, Gudjonsson SA, Palsson A, Thorleifsson G, Pálsson S, Sigurgeirsson B, Thorisdottir K, Ragnarsson R, Benediktsdottir KR, Aben KK, Vermeulen SH, Goldstein AM, Tucker MA, Kiemeney LA, Olafsson JH, Gulcher J, Kong A, Thorsteinsdottir U, Stefansson K (2008) Two newly identified genetic determinants of pigmentation in Europeans. Nat Genet 40(7):835-837. doi:10.1038/ng.160

Voisey J, Van Daal A (2002) Agouti: from mouse to man, from skin to fat. Pigment Cell Res 15:10-18

Yuasa I, Umetsu K, Watanabe G, Nakamura H, Endoh M, Irizawa Y (2004) MATP polymorphisms in Germans and Japanese: the $\mathrm{L} 374 \mathrm{~F}$ mutation as a population marker for Caucasoids. Int $\mathrm{J}$ Legal Med 118:364-366

Yuasa I, Umetsu K, Harihara S, Kido A, Miyoshi A, Saitou N, Dashnyam B, Jin F, Lucotte G, Chattopadhyay PK, Henke L, Henke J (2006) Distribution of the F374 allele of the SLC45A2 (MATP) gene and founder-haplotype analysis. Ann Hum Genet 70:802-811 